\title{
Como entender a cultura brasileira saboreando uma moqueca e batucando com o sistema lógico hiperdialético (SLH)
}

\author{
Mércio Pereira Gomes ${ }^{1}$, Esteban Lopez Moreno ${ }^{1,2}$ \\ ${ }^{1}$ Programa de Pós-Graduação em História das Ciências e das Técnicas e Epistemologia \\ (HCTE), Universidade Federal do Rio de Janeiro \\ ${ }^{2}$ Fundação Centro de Ciências e Educação Superior a Distância do Estado do Rio de \\ Janeiro (Fundação Cecierj) \\ merciogomes@gmail.com, estebanlmoreno@gmail.com
}

Recebido: 24/11/2019 Aceito: 8/12/2019 Publicado: 12/12/2019

\begin{abstract}
In this article we will follow the historical paths that shaped the cultural formation of Brazil. Our main purpose is to try to make Brazilian culture, as we experience it, more understandable and worthy of love, using the Hyperdialetic Logical System and of a metaphor derived from the Brazilian cuisine: the moqueca. Like this delicacy, the formative process of Brazilian culture did not fully and definitively integrate its original matrices, nor indeed exhausted its possibilities of new cultural formations. The idea here is not to understand the whole by the parts, but to launch a new understanding taking into account our cultural matrix.
\end{abstract}

Keywords: Culture. Cultural formation. Brazilian history. Hyperdialetics. Logic. Luiz Sérgio Coelho de Sampaio. Darcy Ribeiro.

Resumo. Neste artigo iremos percorrer a trilha histórica que moldou a formação cultural do Brasil. A intenção desse artigo é buscar tornar a cultura brasileira, tal como a vivenciamos, mais compreensível e digna de amor, pelo uso do Sistema Lógico Hiperdialético e de uma metáfora da culinária brasileira: a moqueca. À semelhança desta iguaria, o processo formativo da cultura brasileira não integrou completamente $e$ definitivamente as suas matrizes originais, nem tampouco esgotou suas possibilidades de novas formações culturais. A ideia não é compreender o todo pelas partes, mas lançar novos entendimentos a partir de nossa matriz cultural.

Palavras-chave: Cultura. Formação cultural. História do Brasil. Hiperdialética. Lógica. Luiz Sérgio Coelho de Sampaio. Darcy Ribeiro. 


\section{Preâmbulos}

O Sistema Lógico Hiperdialético (SLH) é uma filosofia criada pelo brasileiro Luiz Sérgio Coelho de Sampaio, como um sistema epistemológico próprio, que tem aplicabilidade na compreensão tanto do fenômeno humano, em toda sua dinâmica e variação histórica, quanto das características físicas da natureza. O SLH tem sido aplicado em estudos sobre a economia, a física, os fundamentos da matemática, a psicologia e, no caso de um dos autores deste trabalho, sobre a cultura brasileira e antropologia. Sampaio dedicou boa parte de sua vida, conforme suas próprias palavras, "à explicitação dos determinantes lógicos (a priori) de cada um dos grandes campos do conhecimento, na esperança de chegar, oxalá, a um "compacto" do saber formal básico do Ocidente". Seu objetivo era ousado e foi alcançado por meio da configuração de seu sistema de lógicas (SAMPAIO, 2000, 2001).

Entretanto, o SLH parece à primeira vista como algo bastante complicado e por vezes inescrutável. Pois, como entender algo que não é nem simplesmente dual, nem triádico, nem mesmo quaternário, mas sim quinquenário!

A intenção desse artigo é buscar tornar a cultura brasileira, tal como a vivenciamos, mais compreensível e palatável pelo uso de uma metáfora e de uma aplicação. A metaforizarão será feita por meio da elaboração de um prato bastante comum da culinária brasileira e a aplicação concomitante será obtida por uma concisa explicação do processo de formação da cultura brasileira. Esperamos que esse exercício seja bastante satisfatório.

O SLH, ou filosofia sampaiana, é epistemologicamente constituído de cinco modos, ou lógicas, que determinam os possíveis modos de ser no universo e de pensar. Isto quer dizer que aquilo que existe na realidade revela-se também no pensar humano. Por conseguinte, para Sampaio, nada do real se inventa ou se descobre, efetivamente, apenas se desvela ao pensamento humano. As lógicas constitutivas do SLH são: a lógica de Identidade (I), a lógica da diferença (D), a dialética (I/D) e a lógica sistêmica (D/2), cada uma funcionando em seu próprio mérito, e juntas dialogando sob a égide de uma lógica regente, que é a lógica hiperdialética (I/D2), que dá nome ao sistema.

O SLH reconhece que tanto o ser (o universo em toda a sua diversidade e historicidade) quanto o pensar (o ser humano tomando consciência deste ser) estão inseridos em um processo de origens e transformações. Eis porque, antes da lógica própria da identidade (I) existem lógicas antecedentes que, para designar com propriedade, devem ser consignadas como pré-lógicas. Por princípio de simetria, haveria também lógicas que estariam além e acima do conjunto quinquenário, isto é, lógicas mais englobantes que aquelas que podem ser pensadas por seres humanos. Trataremos aqui apenas das duas pré-lógicas que antecedem a lógica da identidade e da diferença, respectivamente, as pré-lógicas I e pré-lógica $D$, ou para simplificar: Pré-I e Pré-D. Portanto, podemos usar o SLH como base lógico-filosófica para traçarmos um modelo culinário que corresponda e facilite a compreensão do processo cultural brasileiro.

Desde já advertimos que as lógicas sampaianas não possuem qualquer relação com categorias aristotélicas, muito menos com raça ou etnia. Elas são potências de diversas naturezas que regem, impulsionam e limitam as formas de ser (ontologia), pensar (epistemologia) e agir (praxiologia) no mundo.

Neste trabalho mostraremos como as formas de ser e de pensar do SLH podem ser aplicadas para: (1) compreender os principais formadores e os processos orientadores de nossa matriz cultural, (2) relacioná-los para alcançar novos entendimentos de nossa identidade brasileira 
e (3) conjecturar sobre as possibilidades inerentes nesse processo que possam delinear caminhos diversos para o futuro.

\section{A Cultura Brasileira como processo hiperdialético}

O fulcro original da cultura brasileira é resultante da convergência de três matrizes culturais e biológicas - o aborígene indígena, o africano transladado e o europeu ibérico invasor. Aqui se instituiu um processo histórico de intenso conflito, mas também de grande potencial de congraçamento. Ao longo dos três primeiros séculos da colonização, foi se formando um caldeamento de povos, raças e culturas que, nas palavras do gênio de Darcy Ribeiro, resultou em algo parecido com a antiga Roma amalgamadora de gentes, "uma Roma lavada em sangue índio, lavada em sangue negro, melhor, tropical, e que está chamada a representar um importante papel no mundo". (RIBEIRO, D., 1995).

O caldeamento cultural em nosso país, contudo, não se deu ao acaso. Tampouco seguiu uma síntese inequívoca, previsível e permanente. As nossas três matrizes originárias se mesclaram e se moldaram por processos tanto violentos quanto amistosos, em graus variados e diferenciados regionalmente. Ainda que tenha sido dito por muitos autores brasileiros e estrangeiros que a formação do mestiço-mulato, a mistura de europeu com africano, tenha sido a síntese biológica predominante, e que tenha sido consubstanciada por um processo violento, em forma de uma violentação da mulher africana-negra pelo europeu-português, uma espécie de "estupro ancestral", com licença do termo, consideramos que, não obstante o reconhecimento dessa forma de miscigenação ter acontecido devidamente, a grande maioria da mestiçagem brasileira ocorreu na verdade entre indígenas e africanos, nas muitas circunstâncias de encontros e convivências que experimentaram, e que foi formativa da maioria demográfica e cultural do povo brasileiro (GOMES, M.P, 2019).

O povo brasileiro que resultou desse caldeamento biológico-cultural se tornou em sua grande maioria mestiço de corpo e alma. Eis o que nos dizem antropólogos e historiadores como Gilberto Freyre e Darcy Ribeiro. Uma mistura sintética, dialética, criou um novo ser humano biologicamente e culturalmente diferente. Entretanto, na própria formação dessa mestiçagem, o caráter original indígena, o caráter africano e o caráter português, em vários modos, permaneceram e ainda têm razão de ser por si mesmos no mundo mestiço. Isto é, há mestiços sincréticos das três matrizes e há também elementos de raízes originais ainda capazes de impulsionar novas possibilidades de novas sínteses. Em outras palavras, e retomando à ideia da hiperdialética, o processo formativo da cultura brasileira não integrou completamente e definitivamente as suas matrizes originais, nem tampouco esgotou suas possibilidades de novas formações culturais.

Concluímos assim o paralelo entre o processo hiperdialético e o processo formativo cultural brasileiro. Passemos agora para pensar esses dois processos como se fosse o processo de cozimento de uma moqueca.

\section{A moqueca cultural brasileira}

Se até agora estamos com lapsos de compreensão, avancemos para a metáfora culinária, qual seja, a "moqueca". Aqui temos um prato de ingredientes variados, com sabores próprios, que, ao se misturarem uns com os outros, adquirem paladares novos e diferenciados que surpreendem e que evocam mais sabores súbitos e inesperados. É este processo que 
acreditamos que equivalha ao processo formativo cultural brasileiro. Vejamos então como se faz uma moqueca e como cada ingrediente, cada tempero, a forma de cozinhar e os utensílios usados nos dão um sentido da hiperdialética. Cada um deles pode corresponder a um modo ou a uma lógica própria do processo hiperdialético.

\subsection{Ingredientes}

\section{Peixes e mariscos (pré-I)}

Esse item vai corresponder à contribuição básica do elemento indígena na constituição da moqueca. Eles representam a base e o sabor fundamental da moqueca. Sua contribuição à formação brasileira é indubitável.

Com efeito, o que hoje conhecemos como Brasil era então um território com vastas florestas ocupadas por mais de 1.200 etnias indígenas (GOMES, M. P., 2005). Separados no tempo e por um vasto oceano no espaço, os originais nativos brasileiros ficaram de fora da mistura cultural que já estava marcando o convívio entre africanos, europeus e asiáticos. Por um lado, preservaram-se desse processo histórico muito doloroso por uns bons 10.000 anos; por outro lado, sofreram-no terrivelmente a partir do século XVI, e, por pouco, não perderam totalmente suas condições de sobrevivência.

Os autóctones brasileiros, que correspondem a esse momento da pré-lógica I, se caracterizam por formarem sociedades de cunho igualitário, com participação efetiva de todos os membros, mínima hierarquia social, com uma economia baseada em produção agrícola, caça, coleta e pescaria limitada para a sua reprodução em baixo crescimento. Sua espiritualidade identificava a natureza e suas forças em estreita convivência com os seres humanos.

\section{Dendê e pimenta africanas (pré-D)}

Estes são alguns dos ingredientes contribuídos pelos africanos à nossa moqueca. Porém, mais do que ingredientes a contribuição africana se dá no plano da criação, induzida tanto pelo dever do trabalho quanto pelo gozo de resistir e viver.

Os africanos foram transladados ao Brasil na condição de escravos, aqui sofreram este jugo e aqui se transcenderam ao se constituírem como o segundo elemento fundamental na cultura brasileira. Suas culturas originais se baseiam em sociedades semi hierarquizadas, com produção agrícola intensa, com o uso de metalurgia e de alta cerâmica, e espiritualidade manifestada pelo convívio com divindades antropomórficas. Por essas e outras características, as nossas raízes africanas que aqui se frutificaram tem com modo de ser e pensar a pré-lógica $\mathrm{D}$.

\section{Azeite, cebolas, tomates (I/D)}

Os europeus-portugueses vieram ao Novo Mundo para explorar o que podiam dos recursos da terra, do trabalho de indígenas e africanos, sempre com o intuito de retornarem para gozar de suas explorações. Mas aqui se formou uma nova nação e eles foram essenciais nessa formação e sua consistência política.

Os portugueses formaram um reino único e inovador a partir de uma formação cultural e política entre visigodos cristianizados e árabes muçulmanos - sempre com a sombra da Espanha nas suas costas. Uma elite dominou todo o processo de invasão e formação de uma nova nação, da economia exportadora à expansão territorial e ao controle militar. Ao final, 
perderam. Mas deixaram todo o processo de dominação política em ação, controlando de vários modos a maioria do povo que se constituiu também com sua contribuição biológica e cultural, que correspondem a esse momento da lógica I/D. Seu azeite e suas cebolas são imprescindíveis na nossa moqueca.

\section{Sal e tempero a gosto $(\mathrm{D} / 2)$}

Nesses ingredientes, a título de simplificação, estão incluídos todos os povos que vieram a posteriori já na conclusão do processo de formação do Brasil, quando a independência de Portugal já estava efetivamente consolidada, e passaram a engrossar o nosso caldo cultural. Sua contribuição fundamental está na ampliação do sentido de nação, que lhe foi possível de integrar pela abertura criada pela tríade original de portugueses, africanos e indígenas.

Pertencem a este grupo, vindos após a independência, os novos portugueses, espanhóis, italianos, alemães, poloneses, judeus sefarditas e ashkenazi, libaneses e sírios, armênios, e, por fim, japoneses, chineses, sul-coreanos, novos africanos, bolivianos, argentinos, paraguaios e, muito recentemente, venezuelanos.

\subsection{Preparo}

\section{Panela indígena, colher africana, fogo europeu}

A chegada dos europeus-portugueses originais (de lógica I/D) trouxe aos povos indígenas que aqui habitavam (pré-I) o choque de duas lógicas ou modos de pensar notadamente distintos. Os invasores portugueses já conheciam a escrita, tecelagem, domesticação de animais, enquanto os índios desenvolviam uma agricultura sofisticada porém de pequena escala, sem tampouco fazer uso da escrita nem da metalurgia. A igualdade social básico preclui qualquer necessidade de uma sociedade hierárquica e inovadora. Decreto que os índios rapidamente se nutriram das benesses tecnológicas do povo invasor, ao custo de sentirem suas culturas devastadas. Sua espiritualidade, evidentemente incompreendida, encontrou, no entanto, algum abrigo na síntese criada com a espiritualidade africana e com um regime de atuação do catolicismo tridentino mais aberto e acolhedor.

Os africanos (pré-D) caçados e reduzidos à condição de escravos, transladados de suas terras e submetidos ao despotismo avassalador de seus corpos sobreviveram em duras condições de vida porque guardaram na alma sua espiritualidade e souberam-na transmitir aos seus descendentes. Indígenas e africanos se alimentaram mutuamente e conformaram a oposição cultural fundamental para sintetizar, com os portugueses, a cultura original brasileira, a cultura de raiz, a cultura que ainda hoje se vê vivida nas zonas rurais, nas camadas sociais mais pobres das cidades, no meio das possibilidades históricas do nosso presente. A contribuição demográfica, cultural e religiosa, pelo autoctonismo indígena e pela espiritualidade africana, juntos como o processo de miscigenação com o ingrediente português, criaram a base da própria cultura brasileira.

Os conflitos entre os portugueses (I/D) com os índios (pré-I) e os negros (pré-D) fizeram com que estes, na tentativa de confrontar de igual para igual com seus invasores, se alçassem ao modo de ser e pensar de oposição clara, o que corresponde à lógica da diferença (D). Os negros não demoraram a associar em seu imaginário religioso - candomblé e suas variações - santos e elementos da cultura cristã aos seus orixás e suas liturgias. Os indígenas, os que sobreviveram às doenças e matanças, viram, após muitas dúvidas, marchas e contramarchas, 
que seu destino se forjava em novo sentido, e, eventualmente, se constituíram em novo ser com os negros e seus descendentes mestiços.

O povão que se formou desse confluência está aí a aguardar, para resistir, para conformar ou para contribuir diante dos novos movimentos políticos e culturais oriundos da elite de origem mestiça com predominância europeia. $\mathrm{Na}$ verdade, não querem mais simplesmente "aguardar" os acontecimentos, mas dão todos os sinais de estarem prontos para se precipitarem em novas possibilidades históricas da humanidade.

Ao longo dos anos, apesar de seu evidente desprezo filosófico e social, a elite mestiçoeuropeia, tendo construído o seu imaginário a partir de clássicos como Utopia, de Thomas Moore, A origem da desigualdade entre os homens, de Jean-Jacques Rousseau, e Dos Canibais, de Michel Montaigne, de religiosos como o Padre António Vieira e visionários como José Bonifácio e tantos outros, soube aprender com os índios e com os negros que havia outras formas e possibilidades de existência do homem.

\section{O fogo como elemento I/D/2 (heraclitiano), criador e transformador}

No primeiro momento da colonização o caldeamento e as combinações entre os portugueses, índios e negros resultaram numa cultura de tipo lógica I/D, própria do Brasil Colonial. Aos poucos, com as transformações econômicas e políticas surgidas da expansão do capitalismo europeu, dadas no Brasil a partir de diversas ações tomadas pelo Marquês de Pombal e aprofundadas pela independência do Brasil, a chegada de novos imigrantes e a pequena porém consistente industrialização, desvelou-se um novo caminho para o Brasil - a modernidade. Aqui estamos no processo de constituição de uma sociedade do tipo lógica $\mathrm{D} / 2$, uma lógica que busca ser racional e incorpora os elementos culturais e econômicos da modernidade.

Eis portanto onde se encontra o Brasil - bem no meio do espaço-tempo de uma lógica I/D, de origem formativa colonial, e o espaço-tempo de uma lógica $\mathrm{D} / 2$, buscando uma racionalidade universal, mas pensando, sempre em estado de precariedade e indecisão.

\section{Sirva-se sem reservas}

Os desafios de cada cultura, e em cada época, advêm dos ingredientes, dos temperos e no calor necessários para produzi-la Eis que estamos diante da possibilidade da construção de uma Nova Roma tão bem sonhada pelo Darcy. Como já poderia ter dito o nosso mais amado compositor, Tom Jobim, saborear uma boa moqueca não é pra todos. Feito o prato, sigamos ao caminho que nos apetece, sirvamo-nos e provemos esta iguaria chamada Brasil. Bom apetite!

(...) "a convicção a que eu chego é de que uma das coisas mais belas do mundo foi a aventura do Brasil se fazendo a si mesmo. Um povo que constitui um novo gênero humano. Não tem novidade nenhuma em fazer a Austrália: pega um bocado de ingleses e escoceses e joga no terreno vazio e eles matam os índios e ficam lá e fazem uma Inglaterra sem graça [risos]. Isto daqui é bobagem. Mas fazer um gênero humano novo, fundir herança genética e cultural, índia, negra e europeia num gênero humano novo, numa coisa nova, que nunca houve. É isso a aventura brasileira e que eu resumo dizendo que o que nós somos, mesmo, é uma nova Roma." (RIBEIRO, D., 1995) 
(..) "Um povo foi criado pela mestiçagem e por uma convivência específica, que criou uma cultura, com sensibilidade e aspirações; não foi formado pelo Estado, como muitos dizem, e, pior, não é uma massa amorfa e desqualificada por não entrar na liça política, como falam outros. Esse povo mudou, claro, entraram novos imigrantes e novas configurações foram realizadas. Mas seu peso original foi fundamental para que aquilo que havia sido criado em seus dois primeiros séculos tenha permanecido. Qualquer ponto da história do Brasil deve ser visto pelos elementos que o constituíram e pelo que produziram nos anos seguintes" (GOMES, M.P. 2019, p. 2930)

\section{Financiamento}

O presente trabalho foi realizado com apoio da Coordenação de Aperfeiçoamento de Pessoal de Nível Superior - Brasil (CAPES) - Código de Financiamento 001.

\section{Referências}

GOMES, M.P. O Índio na História - O Povo Tenetehara em Busca da Liberdade, 1a Edição, Rio de Janeiro, Editora Vozes, 2002.

GOMES, M.P. O Brasil Inevitável - Ética, Mestiçagem e Borogodó, 1a Edição, Rio de Janeiro, Toopbooks, 2019.

RIBEIRO, D. Entrevista com o antropólogo Darcy Ribeiro no programa Roda Viva, em 17 abril de 1995, Disponível em:

http://www.rodaviva.fapesp.br/materia/63/entrevistados/darcy_ribeiro Acesso em: 23 nov. 2019.

SAMPAIO, L.S.C. de. Lógica Ressuscitada - Sete Ensaios, Rio de Janeiro, EdUERJ, 2000. SAMPAIO, L. S. C. de. A lógica da diferença, Rio de Janeiro, EdUERJ, 2001.

MOREIRA, C. de A. C., GOMES, M. P. In: SCIENTIARUM HISTORIA 8, Rio de Janeiro. Livro de anais do Scientiarum Historia 8, Rio de Janeiro: UFRJ, 2015. Disponível em: http://www.hcte.ufrj.br/downloads/sh/sh8/SH/trabalhos\%20posteres\%20completos/RAFAE L-E-A-LOGICA-COTIDIANA.pdf Acesso em: 23 nov. 2019. 